\title{
Development of an assessment model for predicting public electric vehicle charging stations
}

Shekar Viswanathan D, Jeffrey Appel, Lixia Chang, Irina V. Man, Rami Saba and Ahmed Gamel

\begin{abstract}
Deploying an adequate electric vehicle (EV) charging infrastructure to support the increasing EV market is one of the major strategic goals of the U.S. government. This requires a well-designed EV charging network. The distribution and capability of the existing charging networks in terms of EV population, location, charging rate, and time of charging in San Diego is examined. A mathematical model to calculate the demand number of public Level 2 chargers universally applicable is developed. The study showed that although San Diego has sufficient chargers to accommodate the existing EV's charging demand, the current public charging distribution network is neither well designed nor effectively used. To eliminate the waste resulting from the inefficiently designed charging infrastructure and maximize the usage rate of each charger, it is recommended that the designed optimal model to be utilized and the charging location priority be implemented to improve the availability and accessibility of charging network in the City of San Diego.

Introduction: The purpose of this study is to identify current problems with the existing electric vehicle public charging stations and come up with solutions to improve the availability and accessibility of public charging stations in the City of San Diego. The objective of this research project is also to develop a mathematical model to predict the demand of EV chargers in any city including in the City of San Diego.

Methods: A mix of quantitative and qualitative research methods are used to analyze the problem. The first phase of this project is to determine the study area by identifying the existing problems and issues from existing sources, and formulating hypothesis.

Results: The distribution and capability of the existing charging networks in terms of EV population, location, charging rate, and time of charging in San Diego was examined. A mathematical model to calculate the demand number of public Level 2 chargers for the City of San Diego and for each zip code was developed. Among 361 tested public Level 2 chargers distributed in 34 communities, 66 chargers located at 37 charging stations distributed in 22 communities were found to be nonoperational or damaged but still operational. They accounted for $18 \%$ of the total number of tested EV charging stations and 12.7\% of the total public Level 2 in San Diego. The model tested using data from San Francisco Bay Area, and Los Angeles County matched well to the predictions.

(Continued on next page)
\end{abstract}

\footnotetext{
* Correspondence: sviswana@nu.edu

Department of Applied Engineering, National University, San Diego,

California 92123, USA
} 
(Continued from previous page)

Conclusions: The conclusion is that although San Diego has sufficient chargers to accommodate the existing EV's charging demand, the current public charging distribution network is neither well designed nor effectively used. To eliminate the waste resulting from the inefficiently designed charging infrastructure and maximize the usage rate of each charger, it is recommended that the designed optimal model to be utilized and the charging location priority be implemented to improve the availability and accessibility of charging network in the City of San Diego. This model is easily applicable in the European environment since all the five significant independent variables (B/E - Battery capacity to EV Range Ratio, D-Driver Traveling Distance, $\beta$ - Ratio of EV driver charges away from home, Pref $f_{L 2}$ - percentage that EV driver prefers to charge on Level 2 stations, and $T_{L 2^{-}}$duration of public Level 2 chargers' work per day) are easy to obtain. Hence this proposed model has universal applicability.

Keywords: EV, Level 2 EV charger, Charging distribution network

\section{Introduction}

Bosetti and Longden [1] explained that the innovative electric vehicles (EVs), which generate zero emissions by using rechargeable batteries to substitute gasoline or diesel, are effective in reducing GHG pollution and oil consumption. Hence, Governor Edmund G. Brown Jr. [2] issued an order in March 2012 to install adequate public charging stations to support one million zero-emission EVs on California roadways by 2020 and thus reduce GHG emissions by $30 \%$. To reduce the cost of infrastructure installation and EV users' routine and emergency charging, Romano [3] declared that stakeholders expect the local utilities to leverage their unique experiences and expertise to help install additional public charging stations.

Since the introduction of plug-in electric vehicles (PEVs) in December 2010, their sales have significantly increased year after year [4]. As of September 2014, the sales of PEVs were over 603,000 in the global market and over 259,000 in the U.S. [5]. According to the PEV Collaborative 2014 Annual Report, approximately 40\% or 102,440 of those U.S. market sales were from California. San Diego Gas \& Electric (SDG\&E) confirmed that San Diego and Southern Orange counties leased or sold 10,000 EVs within that same period. Based on the current trend, Melaina and Helwig [6] reported that by 2024, the number of EVs in San Diego would reach 91,000. Chung [7] declared that with the ever-increasing number of EVs on the roadways, the demand for availability and accessibility of EV charging stations has continued to grow exponentially despite the availability of residential chargers. Knutsen and Willen [8] also observed that the availability of adequate public charging stations could increase the electric miles driven and provide an alternative charging option when home charging is unavailable.

Almost 10\% of the existing public chargers in the City of San Diego are damaged, dysfunctional, inaccessible, or inoperable based on data collected from customer reviews
[9]. According to plugshare.com, the nation's largest charging network, there are 178 public charging locations with 583 EV chargers in the City of San Diego as of January 11, 2015. The majority of the charging stations are Level 2 and are of the standard J1772 plug type.

The distribution and capability of charging networks in terms of population, location, charging rate, and time are examined to determine whether there is an adequate number of chargers to support the existing EV demand. Cheng, et.al [10] declared that the unreliable charging services would discourage the adoption of EVs and slow down the deployment of public charging infrastructure. Inevitably, the state's strategic goal of putting 1.5 million zero-emission EVs on the roadways of California by 2025 and reducing 80\% GHG emissions in the transportation sector by 2050 will be hard to achieve.

The inoperable chargers represent the problems of management and maintenance in the charging networks. Few studies have been conducted on the accessibility of EV supply equipment (EVSE). The objectives of this research project are to accomplish the following:

- identify current problems for the existing charging stations, and come up with solutions to improve the availability and accessibility of public charging stations in the City of San Diego

- develop a mathematical model to predict the demand of EV chargers in any city including in the city of San Diego.

\section{Literature review}

Since the introduction of EVs in 2010, research and market analysis have been conducted for evaluating EV market [4]. For the current time, the biggest challenge that faces most EV automakers is the battery life of the vehicle [11]. 
Table 1 Charging priorities at different locations

\begin{tabular}{|c|c|c|c|c|}
\hline ESVE & User profile & Typical venues & Charging time & Miles/Hour charge \\
\hline Level 1 (EVSE) & Parked for $68 \mathrm{~h}$ & $\begin{array}{l}\text { Street/Meters } \\
\text { Parking Garages } \\
\text { Cultural/Sports Centers } \\
\text { Airport (long term)/ Hotels }\end{array}$ & $\begin{array}{l}1-2 \mathrm{~h} \\
2-10 \mathrm{~h} \\
2-5 \mathrm{~h} \\
8-72+\text { hours }\end{array}$ & $3-4$ \\
\hline Level 2 (EVSE) & Parked for $24 \mathrm{~h}$ & $\begin{array}{l}\text { Shopping Centers } \\
\text { Airport (short term) } \\
\text { Streets/Meters } \\
\text { Parking Garages } \\
\text { Cultural/ Sports Centers } \\
\text { Airport (long term)/ Hotels } \\
\text { Highways \& Commuting Roads }\end{array}$ & $\begin{array}{l}0.5-2 \mathrm{~h} \\
<1 \mathrm{~h} \\
1-2 \mathrm{~h} \\
2-10 \mathrm{~h} \\
2-5 \mathrm{~h} \\
8-72+\text { hours } \\
<0.5 \mathrm{~h}\end{array}$ & $\begin{array}{l}\text { 8-20 } \\
\text { (depending on vehicle } \\
\text { onboard charger) }\end{array}$ \\
\hline DC Fast Charging (DCFC) & Quick stop for 5-30 min & $\begin{array}{l}\text { Shopping Centers } \\
\text { Airport (short term) } \\
\text { Highways \& Commuting Roads }\end{array}$ & $\begin{array}{l}0.5-2 \mathrm{~h} \\
<1 \mathrm{~h} \\
<0.5 \mathrm{~h}\end{array}$ & $50-60$ \\
\hline
\end{tabular}

Table 1 illustrates EV drivers' charging preference of different chargers at different types of locations. According to AeroVironment [12], Level 2 charging stations are the best option for charging when EV owners are at work, meeting with friends, or shopping. This gives vehicle owners about 25 miles range when plugged at a station supplying $7.2 \mathrm{kWh}$. Cunningham [13] mentioned that though most electric vehicles are compatible with public Level 2 charging stations, Tesla came up with its own charging stations that are compatible only with the cars it manufactures.

As for DC Fast Charging stations, Saxton [14] defined them as the fastest EV charging option available at this time. With a voltage outlet of $480 \mathrm{~V}$, DC Fast Charging stations can give the owners a full charge in less than $30 \mathrm{~min}$ for 120-mile range vehicles. Gartner [15] explained that public charging stations should be user friendly and easy to use.

PluginCars.com, PlugShare, and Recargo [16] point out that California is the area with the most advanced EV charging infrastructure in North America. However, the government benefits are not the only factor in the growth of sales of electric cars and increased number of EVSE. Bianco, N. et al. [17] assert that the increase in numbers was also triggered by low charging prices and automakers' marketing strategies.

The highest priority for EVs is to be able to charge their vehicles in public without any obstacles. EPRI [18] mentioned that the majority of charging happens at EV owners' homes, in order to make good use of cheap late- night electricity. SANDAG [19] explained that charging EVs at the workplace is a second priority, as EV owners visit these places on a daily basis and sometimes need to charge their vehicles for extended commutes. NAS [20] recommended Level 2 charging stations for EVs with large capacity batteries, as they are the most economical solution to charge publically. NAS [20] stated that despite the high costs and efforts to install EV chargers at home, some owners cannot install them as they do not have garages at home. The location and type of chargers make a big difference in the minds of consumers as they plan to purchase EVs.

The deployment of charging infrastructure is the prerequisite for the spread of electric vehicles. Csonka and Csiszar [21] developed an analytical model based on multi-criteria methods for both the national roads and the counties or districts in Budapest using the existing infrastructure. They acknowledged the need for the development of charging demand model, and their proposed approach does not take this into account. Gnann et al. [22] developed a queuing model to quantify the need for fast charging points as a stochastic process of arriving users at fast charging points. They determined the minimum number of charging points needed to limit the average waiting time of arriving users to a pre-defined value. However, their model does not predict the need for the number of chargers at given location. They admitted that the charging infrastructure needs highly depend on battery sizes and power rates. Kleiner et.al's [23] study introduced a spatial model approach by which to investigate and quantify the number of publicly available charging points required in the future. In addition, their model calculates break-even price premiums for an $11 \mathrm{KW}$ public charging point by applying a techno-economic and demand-driven approach. The aim of their study is to support a spatially differentiated and demand-driven infrastructure development that ensures a desired coverage standard. For this purpose, they developed a calculation model which is applied to cumulated PEV sales and the inventory of publicly accessible charging points, in Germany with the spatial resolution of administrative districts. Comprehensive PEV and public charging 
infrastructure usage data are still rarely available and hence this model is not applicable.

Dimitrios Efthymiou1 et.al [24] developed a genetic algorithm to calculate the required number of $\mathrm{EV}$ charging stations. Unfortunately, this model is too complex for it to be adapted in the U.S. The model requires data such as a list of candidate EV charging points (potential locations), their XY coordinates and the expected charging demand, the distances between the potential charging locations and the expected demand per location. These data are difficulty to obtain in any city and in particular in the U.S. As a result, there is a need for a simpler but effective model to calculate the number of charging stations based on driving habits, type of vehicles and type of charging used by drivers. The model developed in this paper offers a simple approach that takes into account the current deficiencies of public chargers while accounting for the driving habits. In addition, any proposed model should allow the wastes of oversupplied chargers to be decreased while determining the better charging locations. Any proposed model should be applicable in the European environment.

\section{Methodology}

As of January 2015, there are 562 EV charging stations distributed in 178 public locations in the City of San Diego, and 518 of them are Level 2 chargers [9]. To meet Governor Brown's goal of putting 1.5 million zero emission EVs on California roads by 2025, NREL [25] predicted the number of on-road EVs in San Diego City would reach 91,000. They also estimated that the number of public Level 2 charging stations in San Diego in 2020 will reach 1800 during a scenario of higher utilization of home charging and 4200 during a scenario of higher utilization of public charging in order to support this strategic goal. According to the customers' comments from PlugShare, ChargePoint, Blink, \& DOE/AFDC, almost 10\% of the existing public chargers are not accessible or operational due to various reasons. The non-operational chargers not only directly decrease the availability of charging stations in public locations, but also cause economic loss for charging networks and overall negative impacts for EV adoptions.

To identify current problems with the existing charging stations, data was collected from multiple primary sources such as websites, literature reviews, and site surveys. The on-site field surveys along with website research conducted throughout San Diego, from January to February 2015, provided first-hand data for defining the characteristics of the public charging stations. A portable EV Emulator EVE-100 L was used to check and test the functionality, output voltage, and current intensity for the samples. After data collection and analysis, a mathematical model was developed to calculate the demand number of Level 2 chargers in public locations to test the hypothesis.

A mix of quantitative and qualitative research methods are used to analyze the problem. The first phase of this project is to determine the study area by identifying the existing problems and issues from existing sources and formulating a hypothesis. The total number of zip codes in the City of San Diego is 43, of which 11 are placed partially within the city. Therefore, a presentation on the number of EV charging stations organized by zip code could mislead readers. Hence, it was decided to collect information based on communities having Level 2 public chargers.

\subsection{Data collection}

The site surveys in the City of San Diego were conducted to identify the non-operational chargers and the characteristics of charging networks in San Diego. The stratified sampling method was used for this survey. The total number of EV public Level 2 chargers was divided into subgroups by communities and then appropriate samples were selected, including both planned and random samples in each group. For this site survey, each sample had several different characteristics such as location, network provider, accessibility, charging costs, and models.

In this study, a sample size of 221 was calculated by choosing a $95 \%$ confidence level with a confidence interval of 5 and a sample size of 518. A sampling method using preselected and random public Level 2 chargers was adopted. There were 146 planned samples in total. Out of those, 90 were based on negative Internet survey reviews; additionally, another 56 locations representing 1 per community were added. This allowed the testing of all 90 reported problematic chargers and at least 1 location per community in San Diego City. While the minimum sample size requires 221 tested chargers to assure a 95\% confidence level, the sample size for this study was increased to 361 to cover $70 \%$ of the target area so as to get a more accurate result.

To collect the hard data during the site survey, a portable EV Emulator, EVE-100 L manufactured by Gridtest Systems [26] was used to test all the selected samples in the City of San Diego. The dashboard showed a quick test result of pass or fail while comprehensive test data were stored on an external $\mathrm{SD}$ card for further analysis. In order to calculate the demand of Level 2 charging stations in San Diego by zip code, the variables are defined as shown in Table 2. 
Table 2 Analyzing demand number of level 2 EV chargers

\begin{tabular}{|c|c|c|c|}
\hline Variables data plan to collect (Where $i$ is the EV user $i$ ) & Type of data & & Method of collection \\
\hline EV User i's Daily Travelling Distance & Quantitative & $D_{i}$ & $\begin{array}{l}\text { Review scientific researches; } \\
\text { check government- } \\
\text { related websites }\end{array}$ \\
\hline $\begin{array}{l}\text { EV User i's Charging Behavior (The percentage of EV } \\
\text { User's Charging Away from Home) }\end{array}$ & Quantitative & i & Review scientific researches \\
\hline $\begin{array}{l}\text { EV User i's Preference of Type of Chargers in Public } \\
\text { (L1, L2, or DC Fast Charger) }\end{array}$ & Quantitative & $\begin{array}{l}\operatorname{Pref}(L \mid)_{i} \cdot \operatorname{Pref}(L 2)_{i}, \\
\text { or } \operatorname{Pref}(L 3)_{i}\end{array}$ & Observe directly during site survey \\
\hline EV i's Electric Range & Quantitative & $\mathrm{R}_{\mathrm{i}}$ & Review scientific researches \\
\hline EV i's Battery Capacity & Quantitative & $\mathrm{B}_{\mathrm{i}}$ & Review scientific researches \\
\hline $\begin{array}{l}\text { Duration of Public Charger Work Per Day (L1, L2, or DC } \\
\text { Fast Charger) }\end{array}$ & Quantitative & $T_{L 1}, T_{L 2}$, and $T_{D C}$ & Observe directly during site survey \\
\hline $\begin{array}{l}\text { The Output Power of Public Chargers Supply (L1, L2, or } \\
\text { DC Fast Charger) }\end{array}$ & Quantitative & $P_{L 1}, P_{L 2}$, and $P_{L 3}$ & Review scientific researches \\
\hline
\end{tabular}

A quantitative data collection method was used to collect the data during site surveys, literature reviews, and analysis of government-related websites.

\subsubsection{Samples selection and testing}

The planned samples were selected based on the comments of EV users posted on PlugShare. These comments include 1430 negative reviews and 487 positive reviews. The comments were then identified and categorized into technical problems, limits in accessibility, and availability. The top three problems of existing charging networks stem from out of order, requiring a special permit, and broken touchscreen. Based on the posted complaints, 90 chargers with negative reviews were targeted as the precedent planned samples. Using the sampling method developed in this work, 361 out of 518 public Level 2 chargers were tested, which incorporated 146 planned samples and 215 random samples, in 56 communities and 26 zip codes. There are 52 communities in San Diego, 3 recreational zones (Balboa Park, Los Peñasquitos Canyon Preserve, Mission Bay Park) and the San Diego International Airport. The last four zones do not belong to any community, but they are located within the city and contain EV charging stations. However, the word community was used to conditionally define these four territories. The uptown community, which has only one location with EVSE, was not tested due to limited access to the parking lot. Twenty or $38 \%$ of the neighborhoods in the city do not have charging stations. This could be considered in the design of EV charging stations in these regions, specifically, in terms of the number of EVs by using the proposed model in this work.

\subsection{Model development}

To calculate the demand number of public Level $2 \mathrm{EV}$ charging stations in the City of San Diego by zip code, a model developed as shown in Eq. (1) is used to compute and analyze the collected data based on different typical scenarios.

$$
L_{2}(\text { Demand })=\frac{\sum_{i=1}^{N} C_{i} \cdot \beta_{i} \cdot \operatorname{Pr} e f_{i, L 2}}{P_{L 2} \cdot T \cdot L 2 .}
$$

where:

$i$ The EV user $i$

$N$ The number of EV in the target area

$C_{i}$ EV driver $i$ 's daily consuming power.

$\alpha_{\mathrm{i}}$ The percentage of electricity that EV driver $i$ charge at home.

$\beta_{i}$ The percentage of electricity that EV driver $i$ charge in the public stations.

Constraints: $\alpha_{\mathrm{i}}+\beta_{i}=1$

Pref $_{i, L 1}$ The percentage that EV driver $i$ prefers to charge on Level 1 stations.

$\operatorname{Pref}_{i,}{ }_{22}$ The percentage that EV driver $i$ prefers to charge on Level 2 stations.

$\operatorname{Pref}_{i, D C}$ The percentage that EV driver $i$ prefers to charge on DC Fast Charging stations.

Constraints: Pref $_{i, L 1}+\operatorname{Pref}_{i, L 2}+\operatorname{Pref}_{i, D C}=1$

$P_{L 2}$ The output power (watts) of public Level 2 chargers supply while they are charging

$T_{L 2}$ The duration of public Level 2 chargers' work per day (hours).

EV drivers' daily consuming power $(\mathrm{Ci}$ ), multiplied by the percentage they charge in the public locations $\left(\beta_{i}\right)$ determines their daily-required power in public locations. The EV drivers' daily-required power in public locations multiplied by the percentage EV drivers' preference of charging on Level 2 stations determines their daily-required power on public Level 2 charging stations. The demand power on public Level 2 charging stations divided by the 


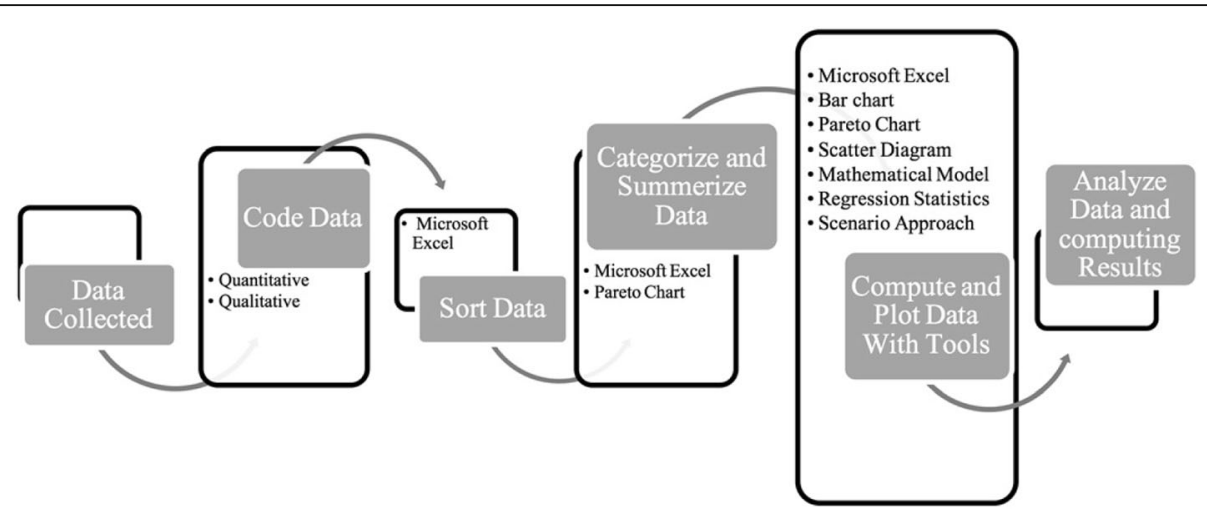

Fig. 1 Data Analysis Tools Used

output power of Level 2 chargers $\left(P_{L 2}\right)$ and the duration of work in each day $\left(\mathrm{T}_{L 2}\right)$ determine the demand number of public Level 2 chargers in the study area. The EV drivers' daily consuming power (Ci) can be calculated through Eq. (2). The EV i's battery capacity ( $\mathrm{kWh}$ ) divided by its electric range (miles) determines the amount of $\mathrm{kWh}$ the EV $i$ consumes per mile driven. The daily driving distance multiplied by the amount of $\mathrm{kWh}$ the EV i consumes per mile drive determine its daily consumed power $(\mathrm{kWh})$.

$$
C_{i}=\frac{B_{i}}{E_{i}} \cdot D_{i}
$$

where

$B_{i}$ EV $i$ 's battery capacity (kWh).

$E_{i} \mathrm{EV} i$ 's electric range (miles).

$D_{i}$ EV driver $i$ 's daily travelling distance.

Integrating Eq. (1) and (2), the demand number of public Level 2 charging stations can be calculated using Eq. (3). The output voltage $\left(\mathrm{U}_{L 2}\right)$ of a Level 2 charger

Table 3 The number of EVSE in San Diego

\begin{tabular}{|c|c|c|c|c|}
\hline \multirow{2}{*}{$\frac{\text { Level }}{\text { Outlets (Local) }}$} & \multirow[t]{2}{*}{ Type } & \multicolumn{2}{|c|}{ Number of the stations } & \multirow{2}{*}{$\begin{array}{l}\text { Number of the public locations } \\
176\end{array}$} \\
\hline & & & & \\
\hline \multirow[t]{3}{*}{ Level 1} & Wall Outlet (120v) & 37 & 40 & \\
\hline & Nema $14-50$ & 3 & & \\
\hline & EV Plug (J1772) & 504 & 508 & \\
\hline \multirow[t]{2}{*}{ Level 2} & Tesla HPWC (Roadster) & 2 & & \\
\hline & Tesla HPWC (Model S) & 2 & & \\
\hline \multirow[t]{3}{*}{ DC Fast Charging } & CHAdeMO DCFC & 17 & 22 & \\
\hline & Tesla Supercharger & 0 & & \\
\hline & SAE Combo DCFC & 5 & & \\
\hline \multicolumn{5}{|c|}{ Outlets (International) } \\
\hline \multirow[t]{4}{*}{ Level 1} & Wall Outlet (BS1363) & 0 & 0 & \\
\hline & Blue Commando & 0 & & \\
\hline & Wall Outlet (Earplug) & 0 & & \\
\hline & Blue Commando & 0 & & \\
\hline \multirow[t]{5}{*}{ Level 2} & Mennekes (Type 2) & 10 & 10 & \\
\hline & EV Plug (Type 3) & 0 & & \\
\hline & Level 1 - & 40 & & \\
\hline & Level 2 - & 518 & & \\
\hline & DC Fast Chargers - & 22 & & \\
\hline TOTAL: & & 580 & & \\
\hline
\end{tabular}


multiplied by the output current $\left(\mathrm{I}_{L 2}\right)$ and then divided by 1000 equals the amount of power $(\mathrm{kW})$ the Level 2 charger supplies while charging $\left(P_{L 2}\right)$. The number of EV registered in the City of San Diego by zip code is already known. Based on research from the literature review, the mean value for variables such as the EV driver's average daily travelling distance, the average percentage of EV drivers' charging away from home, and the average percentage of EV drivers' preference of charging on Level 2 chargers can be determined.

$$
\begin{aligned}
L_{2}(\text { Demand }) & =\frac{\sum_{i=1}^{N} \frac{B_{i}}{E_{i}} \cdot D_{i} \cdot \beta_{i} \cdot \operatorname{Pr} f_{i, L 2}}{P_{L 2} \cdot T \cdot L 2 .} \\
& =N \cdot \frac{\bar{B} \cdot \bar{D} \cdot \bar{\beta} \cdot \operatorname{Pr} e f_{L 2}}{\frac{\overline{U_{L 2}} \cdot \overline{I_{L 2}}}{1000} \cdot \overline{T_{L 2}}}
\end{aligned}
$$

Thus, the ratio between number of public Level 2 chargers and the number of EVs can be calculated through Eq. (4).

$$
\begin{aligned}
& \frac{L_{2}(\text { Demand Number })=}{N}= 1000 \\
& \frac{\bar{B}}{} \cdot \bar{D} \cdot \bar{\beta} \cdot \operatorname{Pr} f_{L 2} \\
& \overline{U_{L 2}} \cdot \overline{I_{L 2}} \cdot \overline{T_{L 2}}
\end{aligned}
$$

The basic assumption of this model is that the total demand power of the existing EVs equals the nominal output power of the installed chargers. National Renewable Energy Laboratory (NREL) applied a similar concept to calculate the demand number of chargers [25]. However, the way to calculate the total demand power is different and hence the results obtained are different.

The total demand power in NREL's model is the total consumed electricity on the charging events for the PEVs (kWh/day). Two functions were used in this model: one is the function of installed EVSE capacity and peak hourly demand $(\mathrm{kW})$; and the other one is the function of electricity used by PEVs (kWh) through calculating the charging events and points on the installed EVSE [25]. The estimation is based on the assumption

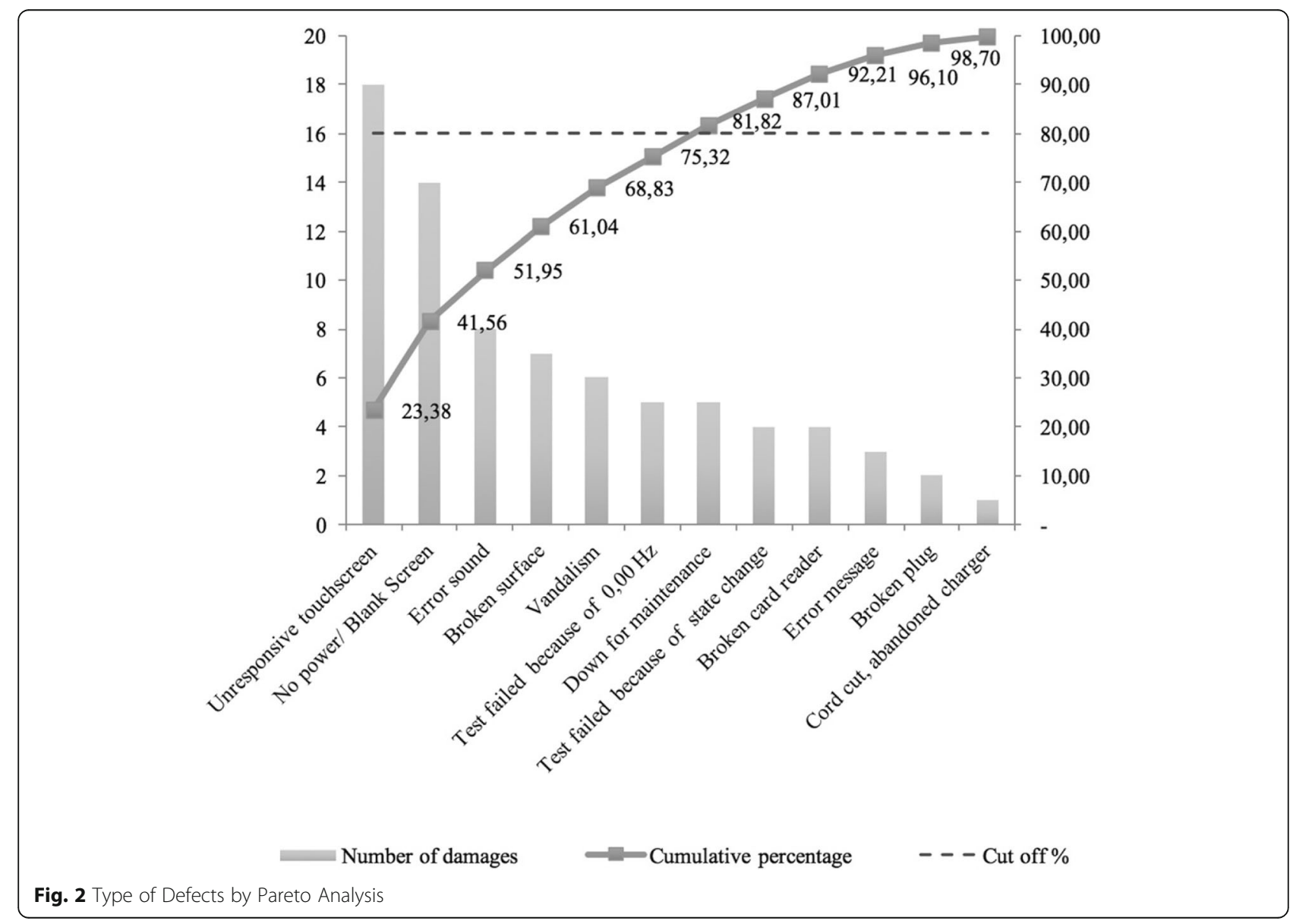




\section{Number of tested EVSE by location type}

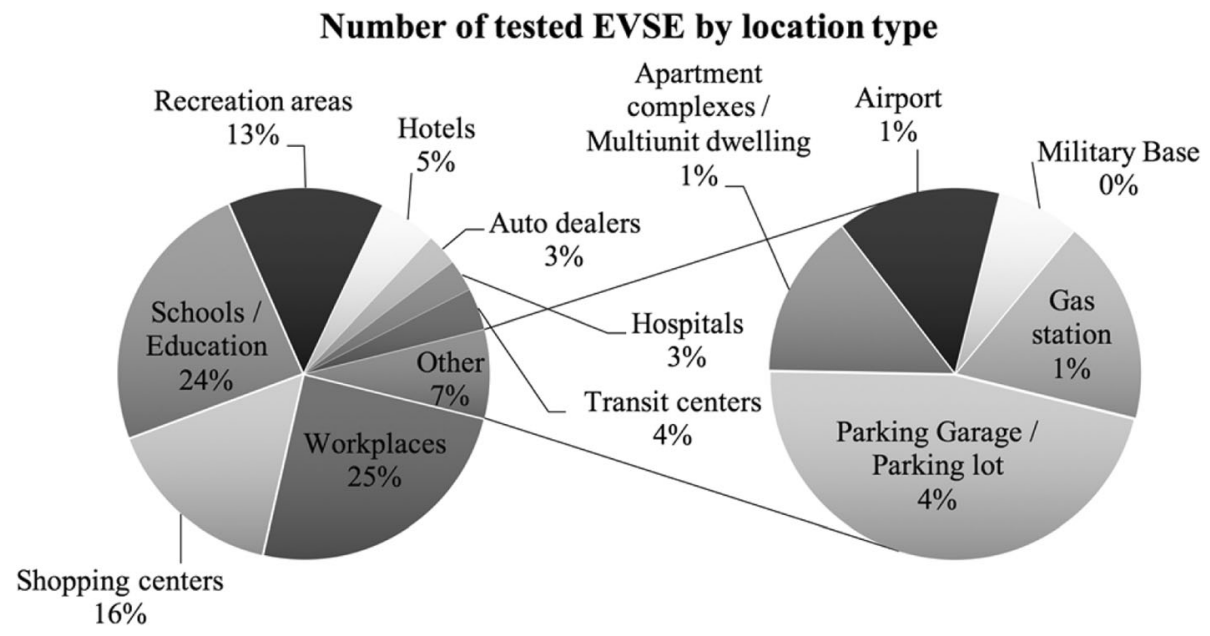

Fig. 3 Distribution of Tested EVSE by Location

of the number of charging points and charging events in the locations. These types of data can be obtained from on-site observations with sufficient number of installed EVSE in the assigned locations. The results may vary and be inaccurate because EV drivers might change to other charging locations if the App shows that the chargers are occupied or inaccessible. The EV drivers might change their charging preference to home as well if the charging locations are installed at unsuitable locations.

The total demand power in the proposed model is the electricity demand to accommodate the existing number of registered EVs. Using the existing number of EVs, the EVs' battery capacity, electric range, and the EV driver's daily driving distance, their preference of charging in public and on different type of EVSE the bottom line of the demand EVSE at each location is calculated. A market survey form was also developed to collect the data for this formula for the targeted locations. This model can estimate the demand number of chargers at any specific locations in a more logical and accurate way. Thus, comparing with NREL's model, the model proposed is an improved one and is more accurate and reliable. Using the proposed model, the wastes of oversupplied chargers can be effectively decreased and the better charging locations can be determined.

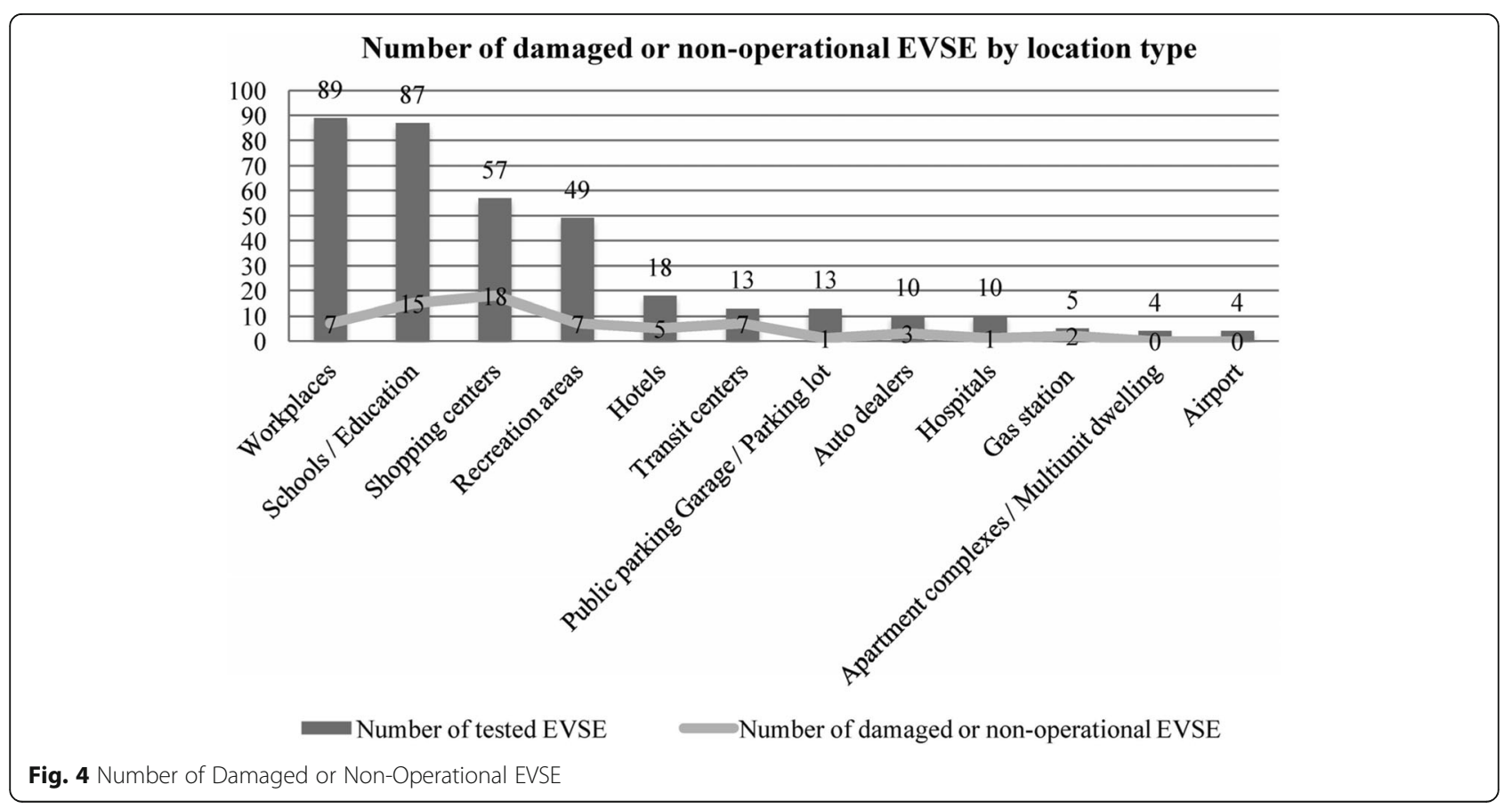




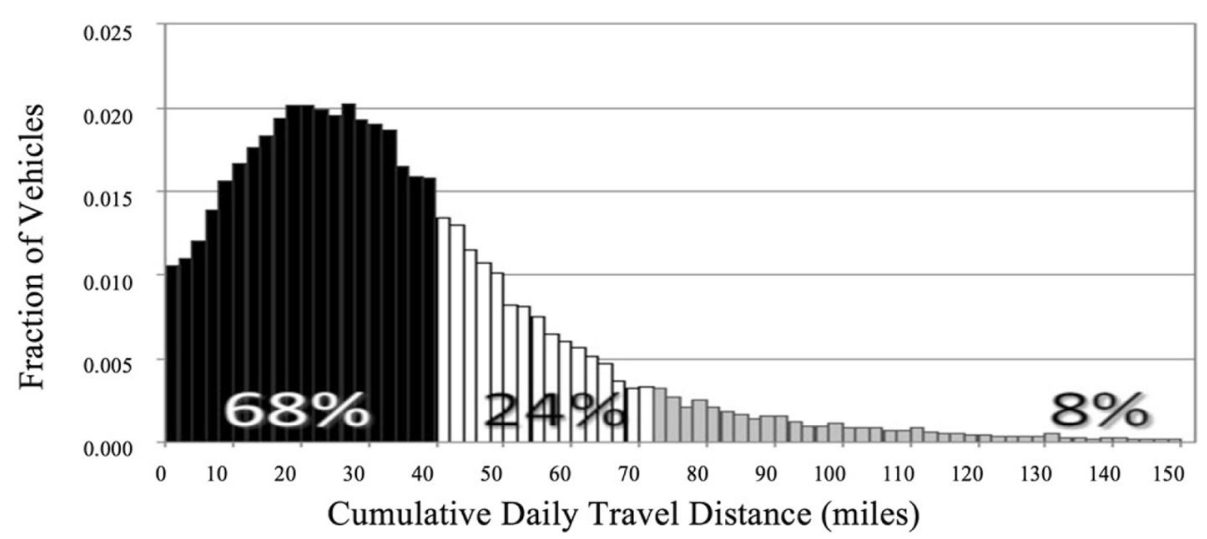

Fig. 5 Cumulative Daily Travel Distance

To analyze the distribution model of public Level 2 chargers in San Diego, statistical techniques were used using the data collected.

Figure 1 shows the procedure of data analysis with the specific tools used. A mathematical model to analyze the relationships between different variables and utilize the regression statistical analysis to find the significance among them is developed. Due to the uncertainties and difficulties in collecting the accurate data from each EV driver, the scenario approach is applied to the process of data computation and analysis.

\section{Results and discussion}

The results of the Internet survey indicate that the City of San Diego has 580 public chargers distributed in 176 locations as presented in Table 3.

The most popular EV charging stations in San Diego are 518 Level 2 stations with the J1772 EV plug type, encompassing $89 \%$ of the market. By mapping exact quantity for each type of charger by location, one can show that the largest number of EVSE is located in the western and central parts of the city. This process was utilized as a tool to aid in selecting the planned and random samples for the site survey.

\subsection{Number of nonoperational chargers}

Among 361 tested public Level 2 chargers distributed in 34 communities, 66 chargers located at 37 charging stations distributed in 22 communities were found to be nonoperational or damaged but still operational. They accounted for $18 \%$ of the total number of tested EV charging stations and $12.7 \%$ of the total public Level 2 in San Diego.

A review of nonoperational and defective Level 2 chargers showed that the largest number of tested charging stations is in Downtown/Centre City, Kearny Mesa, and Mira Mesa. The highest number of both damaged and non-functional EVSE were found in Sabre Springs, which were precisely eight EV charging stations. The next in number was in Mission Valley and in Downtown/Centre City, each with seven EV charging stations. Two out of three chargers in Midway Pacific Hwy were found to be out of service thus accounting for
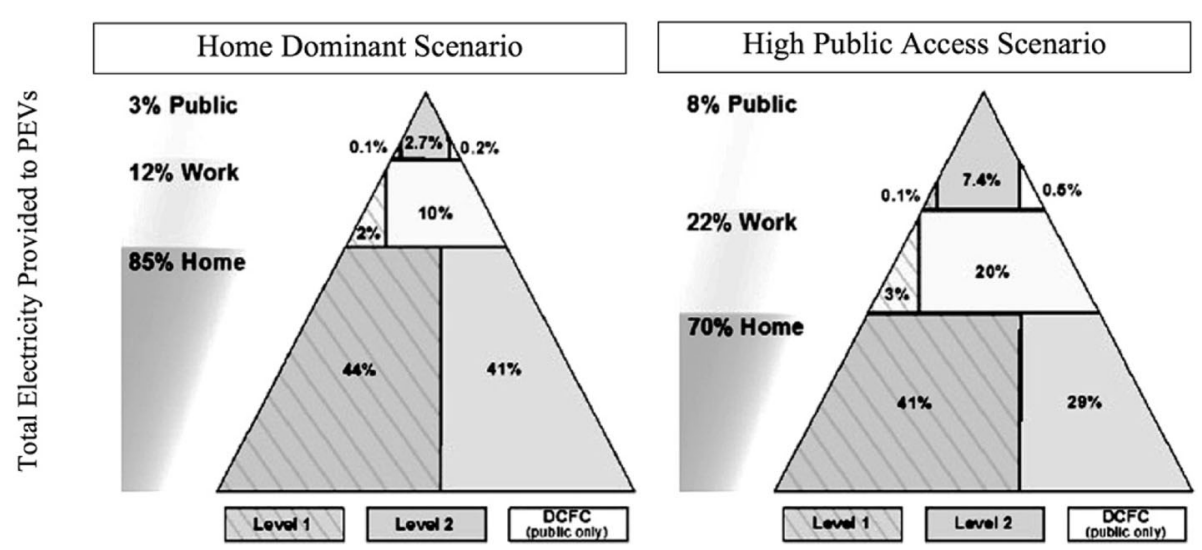

Fig. 6 Electricity Distribution to PEVs 
$67 \%$ of the total public Level 2 chargers in this community. This ratio indicates the lack of EV charging capacity in that community. The defective chargers were not fixed during visit thus providing the insight into the charging network's management and maintenance issues.

During site survey, 11 charging networks were tested. It was noted that the Blink network has the largest number of broken charging stations. Out of the 236 Level 2 chargers in Blink network, 52 were found defective. None of the 56 tested chargers in ChargePoint was found problematic. However, the testing could only be performed in free EVSE and Blink network stations (another EV network Management) due to the availability of the Blink network card. Therefore, the results for paid EVSE from other networks were based only on visual inspection. In addition to data on functional status, this table also indicates cost and the availability of chargers.

\subsubsection{Characteristics of the damaged, dysfunctional, or inoperable chargers}

The observed problems while conducting site surveys on the EV charging stations in the City of San Diego were categorized. The six main categories namely electrical faults, physical problems, hardware faults, software problems, vandalism and others were formed based on customers' reviews that contained technical or physical EV charger complaints. The most common issues were attributed to electrical faults and software problems.

Figure 2 highlights the most common problems such as unresponsive touchscreen and electrical faults. These represent $41.56 \%$ of all damages and give rise to the almost $90 \%$ of negative reviews thus requiring more attention.

\subsection{Characteristics of the public level 2 charging stations}

The City of San Diego has 52 communities. In addition, there are four territorial areas with the presence of EV charging stations. Twelve of these communities contain $80 \%$ of all EV charging stations in San Diego. Three of these communities, namely University, Downtown, and Kearny Mesa, represent $40 \%$ of the EVSE market in the city. This existing charging distribution by communities provides the information relating to the demand for the number of public chargers based on the different characteristics of communities. For example, University and Kearny Mesa are the communities that have the largest employers and schools, and Downtown has a cluster of attractions, shopping centers, and restaurants people visit often. The site survey recorded the types of locations for 361 tested EV charging stations. The number of tested chargers by types of the locations are displayed in Fig. 3.
Table 4 (EB) Value for five typical EVs

\begin{tabular}{llll}
\hline Typical EV type & $\begin{array}{l}\text { Battery capacity } \\
\text { (kWh nominal) }\end{array}$ & $\begin{array}{l}\text { Electric range } \\
\text { (miles) }\end{array}$ & $\begin{array}{l}\text { B/E } \\
\text { (kWh/mile) }\end{array}$ \\
\hline 2013 Toyota Plug-in Prius & 4.4 & 11 & 0.40 \\
2013 FordC-Max & 7.6 & 21 & 0.36 \\
2013 Chevrolet Volt & 16.5 & 38 & 0.43 \\
2012 Nissan Leaf & 24 & 73 & 0.33 \\
2013 Tesla Models & 85 & 265 & 0.32 \\
\hline
\end{tabular}

The largest number of stations are installed in workplaces and account for $25 \%$ of the total number of stations. Schools and education account for $24 \%$ and shopping centers account for $16 \%$.

Figure 4 shows the number of damaged stations per location type. It can be clearly seen that the highest number of damaged EVSE were located in workplaces, shopping centers, schools/education, and recreational areas perhaps due to overuse. This could also be due to lack of maintenance and management, or proper knowledge on how to operate EVSE stations, vandalism, or overuse.

\subsection{Accessibility of public charging stations during site survey}

Accessibility of EVSEs can increase the usage rate of the charging stations. Several factors such as the number of charging stations in use, price for parking and charging, and permit requirements affect accessibility. In this work, it was observed that 82 EVSE stations were in use during the working hours from 8:00 AM to 5:00 PM during the research period. 239 EVSE stations were available for use and 40 other stations were non-operational due to testing errors. This indicates that the usage rate for public charging stations is low. The reason may be that there are oversupplied chargers or they are placed in inconvenient locations. While testing different EVSE stations, it was observed that almost half of the total number of locations required special permits to use the stations and this could be the reason for limiting access to their use. The greatest number of charging stations with permits were located in schools, workplaces, hotels, and hospitals. Some places have dedicated parking spots for Car2Go. It was also observed that some EVSEs require additional parking cost beyond the

Table 5 Output of regression analysis

\begin{tabular}{ll}
\hline Regression Analysis & \\
\hline Multiple R & 0.867046458 \\
R Square & 0.75176956 \\
Adjusted R Square & 0.674197548 \\
Standard Error & 0.054120181 \\
Observation & 22 \\
\hline
\end{tabular}


Table 6 Output of ANOVA analysis

\begin{tabular}{|c|c|c|c|c|c|}
\hline \multicolumn{6}{|c|}{ ANOVA analysis } \\
\hline & Df & SS & MS & $F$ & Significance $F$ \\
\hline Regression & 5 & 0.141928027 & 0.028386 & 9.691247343 & 0.000209788 \\
\hline Residual & 16 & 0.046863904 & 0.002929 & & \\
\hline Total & 21 & 0.188791931 & & & \\
\hline
\end{tabular}

charging fee. Site survey results indicate that paid parking spots were mostly located in hotels and hospitals. It could be one reason why the usage rate of these chargers is low.

\subsection{Calculating the demand number of public level $2 \mathrm{EV}$ chargers in San Diego \\ 4.4.1 Simulation model}

Using the model developed, the demand number of public Level $2 \mathrm{EV}$ chargers can be calculated. The data for seven independent variables $\left(\frac{B}{E}\right), \mathrm{D}, \beta, \operatorname{Pref}_{L 2}, U_{L 2}, I_{L 2}$, and $T_{L 2}$ in Eq. (4) were collected from on-site surveys and literature reviews.

From Table 4, one can get the value of $\left(\frac{B}{E}\right)$ for five typical EVs. Since there are different types of EVs sold in the market based on various customers' preference, the mean of $\left(\frac{B}{E}\right)$ value is assumed to fall between 0.32 and 0.43 .

From Fig. 5, it is clear that $68 \%$ of the EV users drive a maximum of 40 miles per day and $78 \%$ of the driving distance falls into a range from 5 miles to 50 miles.

From Fig. 6, it is clear that the ratio of EV drivers who charge away from home is between 15\% and 30\%.

Based on the charging cost and charging speed indicated in Fig. 6, it is assumed that the mean Pref $f_{L 2}$ falls into a range between $90 \%$ and $99 \%$. Since EV drivers prefer to charge at home at nights while home charging is available, most of the public charging occurs in the daytime during working hours. In view of this point, it can be assumed that the duration of Level 2 chargers work per day will fall between $2 \mathrm{~h}$ and $8 \mathrm{~h}$.

Based on the above assumptions and Eq. (4), the sample data was computed using the samples method. In this case, there is one dependent variable L2 (Demand) and five significant independent variables (B/E - Battery capacity to EV Range Ratio, D-Driver Traveling
Distance, $\beta$ - Ratio of EV driver charges away from home, $\operatorname{Pref}_{L 2}$ - percentage that EV driver prefers to charge on Level 2 stations, and $T_{L 2^{-}}$duration of public Level 2 chargers' work per day). The regression analysis was used to analyze the relationships between these variables and predict the L2 (Demand) according to the number of EVs.

Table 5 is the output results of the regression analysis. These results provide the accuracy of the overall regression equation. The linear relationship between the L2 (Demand) and the five independent variables is strong and positive as evidenced from the Multiple $R$ value of 0.87 . The $R$ Square value of 0.75 suggests that the five independent variables in Eq. (4) can explain the $75 \%$ variation in L2 (Demand). It also means that $75 \%$ of the values fits this designed model, which is indicative for good prediction. The adjusted R Square is 0.67 , which is more conservative when new independent variables added. Standard error is 0.054 , which means the predicted variation of the ratio of $\mathrm{L} 2$ (Demand)/ $\mathrm{N}$ is 0.054 .

Table 6 shows the output results of ANOVA analysis. Significance of F value indicates only a $0.021 \%$ chance occurred in the output of this regression analysis. It is reasonable to conclude that the output probability is not by chance.

Table 7 shows that the coefficient of Intercept is 0.2214 , and that the coefficient for the five independent variables $\mathrm{B} / \mathrm{E}, \mathrm{D}, \beta, \operatorname{Pref}_{L 2}$, and $T_{L 2}$ are $0.216,0.003$, $0.515,-0.287$, and -0.024 respectively. Thus, the predicted equation of L2 (Demand)/ $\mathrm{N}$ can be formulated as Eq. (5):

$$
\begin{aligned}
& \frac{\mathrm{L}_{2}(\text { Demand })}{N}=0.2214+0.216 \times\left(\frac{\bar{B}}{\bar{E}}\right)+0.003 \times \bar{D}+0.515 \times \bar{\beta}+ \\
& (-0.288) \times \overline{\operatorname{Pr} e f_{L 2}}+(-0.024) \times T_{L 2}
\end{aligned}
$$

From the output of the $p$-value shown in Table $7, T_{L 2}$, $D$, and $\beta$ have a significant relationship with L2 (Demand). On the other hand, B/E and $\operatorname{Pref}_{L 2}$ have an insignificant relationship with L2 (Demand) in this regression model. According to the EV report of Smart and Schey [27], the mean percentage of EV customers

Table $\mathbf{7}$ Intercept accuracy and independent variable's coefficient

\begin{tabular}{lllllll}
\hline & Coefficients & Standard Error & t Stat & $P$-value & Lower 95\% & Upper 95\% \\
\hline Intercept & 0.221358615 & 0.418782524 & 0.528577 & 0.604354671 & -0.666420676 & 1.109137906 \\
B/E (kWh/mile) & 0.216271398 & 0.411759224 & 0.525238 & 0.606620722 & -0.656619162 & 1.089161959 \\
$D$ (miles) & 0.003101176 & 0.000876036 & 3.540008 & 0.002723391 & 0.001244062 & 0.00495829 \\
$\beta(\%)$ & 0.515155979 & 0.233539355 & 2.205864 & 0.042361745 & 0.020074662 & 1.010237296 \\
Pref & -0.286983903 & 0.408471641 & -0.70258 & 0.492413826 & -1.152905099 & 0.578937293 \\
T $_{\text {L2 }}$ (hour) & -0.023985166 & 0.006298995 & -3.80778 & 0.00154714 & -0.03733844 & -0.010631893 \\
\hline
\end{tabular}


Table 8 Ratio of L2 (Demand) N and demand number of level 2

\begin{tabular}{lllll}
\hline $\begin{array}{l}T_{L 2} \text { (Duration of } \\
\text { Working hours per day) }\end{array}$ & Ratio (L2 Demand/N) & $\begin{array}{l}\text { N (Number of EVs in } \\
\text { San Diego) }\end{array}$ & $\begin{array}{l}\text { Demand number } \\
\text { of level 2 }\end{array}$ & $\begin{array}{l}\text { Actual number of level } \\
2 \text { in San Diego }\end{array}$ \\
\hline 2 & 0.162 & 4667 & 758 & 518 \\
3 & 0.138 & 4667 & 646 & 518 \\
4 & 0.114 & 4667 & 534 & 518 \\
4.01 & 0.1109 & 4667 & 518 & 518 \\
5 & 0.090 & 4667 & 422 & 518 \\
6 & 0.066 & 4667 & 310 & 518 \\
7 & 0.043 & 4667 & 198 & 518 \\
\hline
\end{tabular}

charged in public locations is $18 \%$, which falls in the range between $15 \%$ and $30 \%$.

Percentage of EV Driver's Charging on Level 2 is $96 \%$ and mean B/E: 0.36 .

Using Eq. (5), the ratio of $\mathrm{L} 2$ (Demand)/ $\mathrm{N}$ and the demand number of Level 2 chargers in terms of different duration of working hours were calculated as in Table 8:

The results show that the demand of each charger depends on the available duration of the charger per day. For instance, the registered number of EVs in San Diego city in 2015 is 4776; if the average hours of each charger work per day is $6 \mathrm{~h}$, the ratio is 0.0665 and the demand number of Level 2 chargers is 310 . On the other hand, if the average hours of each charger work per day is $3 \mathrm{~h}$, the ratio is 0.1145 and the demand number of Level 2 chargers is 646. San Diego needs 336 more chargers if each charger works $3 \mathrm{~h}$ per day. To support the same amount of EVs charging in public locations and to effectively decrease the cost of creating charging stations, the Level 2 chargers would have to work for $6 \mathrm{~h}$ per day after deducting the time lost between different customer's charging events, as shown in Table 9.

In this optimal model, the ratio of demand of EVSEs to the number of EVs is 0.0665 and the bottom line of the demanded public Level 2 charger is 310 . The City of San Diego has 518 Level 2 chargers in the market for public use, which is 208 chargers more than the demand number.

Melaina and Helwig [6] predicted the number of EVs in the City of San Diego would rise to 91,000 by 2020 to meet Governor Brown's goal of putting 1 million ZEVs on California roads. Utilizing this optimal model, the demand number of Level 2 chargers for the public and workplace would be 6051. Comparing the existing 518 public Level 2 chargers, there is a gap of at least 5533 chargers needed to accommodate the EV market's growth. This result confirms our hypothesis and proves that there is a sustainable potential market for the public Level 2 chargers in the City of San Diego. At the time of this study, the percentage of broken stations to the total number of stations in San Diego was approximately $18.5 \%$, and hence when planning demand, it is necessary to increase the number of charging stations by at least $15-20 \%$ above the model prediction.

\subsection{Comparison between top EV friendly cities}

A comparison of the charging infrastructure for the San Francisco Bay Area, Los Angeles County, and the City of San Diego was conducted to garner a ratio of the number of PEVs to one public Level $2 \mathrm{EV}$ charging station per city. Data for the total number of PEVs in the San Francisco Bay Area and Los Angeles County was captured at the Clean Vehicle Rebate Project (CVRP) rebate statistics site maintained by the Center for Sustainable Energy. The number of PEVs for the City of San Diego was determined using the DMV registration data provided by SDG\&E.

The U.S. Department of Energy's [28] Alternative Fuel Data Center provides data download for alternative fuel stations. This data was used in calculating the number of public Level 2 charging stations in the San Francisco Bay Area and Los Angeles County.

As shown in Table 10, Los Angeles County has the lowest ratio at one public Level 2 charging station, which was 22.8 PEVs. It was closely followed by the San Francisco Bay Area at one public Level 2 charging station, which was 18.5 PEVs. The City of San Diego has the highest

Table 9 Selected optimal model

\begin{tabular}{lcccc}
\hline$T_{L 2}$ (Duration of working hours per day) & Ratio (L2 Demand/N) & $\begin{array}{l}\text { N (Number of EVs in } \\
\text { San Diego) }\end{array}$ & $\begin{array}{l}\text { Demand number } \\
\text { of level 2 }\end{array}$ & $\begin{array}{l}\text { Actual Number of level 2 } \\
\text { in San Diego }\end{array}$ \\
\hline 6 & 0.066 & 4667 & 310 & 518 \\
\hline
\end{tabular}


Table 10 The Ratio of PEVs to one level 2 public charging station

\begin{tabular}{lllll}
\hline & U.S census population (2014) & Total PEVs & Public level 2 charging stations & Ratio: 1 lharging station to number of PEVs \\
\hline San Francisco Bay Area & 7.56 million & 39,167 & 2120 & $1: 18.5(5.41 \%)$ \\
Los Angeles County & 10.17 million & 26,908 & 1180 & $1: 22.8(4.39 \%)$ \\
San Diego City & 1.35 million & 4667 & 518 & $1: 9(11.10 \%)$
\end{tabular}

ratio; for everyone public Level 2 charging station, there are 9 PEVs. The results show that the City of San Diego could potentially have less than half the congestion found at public Level 2 charging stations in Los Angeles County or the San Francisco Bay Area. It indicates that the City of San Diego's current infrastructure could support a $50 \%$ increase of PEVs and remain within the thresholds of the San Francisco Bay Area's current ratio.

Table 10 shows the ratio (Number of Chargers to Number of EVs) in San Francisco Bay area and Los Angeles is $5.41 \%$ and $4.39 \%$ respectively, which is very close to the ratio of $6.6 \%$ developed in the optimal model. The result supports the validity of the optimal model. This model has an error margin of $1.2 \%$, which is good for the predicting number of chargers required for a given number of EVs. This error margin works when the chargers are not effectively used due to the limited accessibility to the chargers and the changes of $\mathrm{EV}$ drivers' charging behavior.

Based on the above analysis, except for the 66 nonoperational chargers found on site survey, San Diego has 452 public Level 2 chargers available for customer use, which is more than enough for the market demand of 331 chargers. The main cause of the low usage rate stems from the barrier of accessibility. The accessibility data collected during site survey indicates that 188 out of 361 chargers had public accessibility for customers; however, only 41 of them were in use. This suggests the need for optimizing the distribution of public Level 2 charging stations and improving their accessibility.

\subsection{Location distribution analysis by zip code}

Using the DMV's registered number of EVs as provided by SDG\&E, some of the demand number of Level 2 chargers were calculated by zip code using the optimal model as shown in Table 11.

The actual number minus the demand number of public Level 2 chargers that San Diego has at present will determine the new chargers the city needs to install to meet current EV customers' demands.

The zip codes with a negative value on the number of new chargers means that they do not have enough chargers to accommodate the EV driver's demands. The positive value indicates that these zip codes are enough to accommodate the EV drivers in those areas.

During the site surveys and literature reviews, it was identified that the workplace is a key location in which EV users charge their vehicles away from home. The reason can be attributed to eight hours spent daily in the workplace. The other charging locations are shopping centers, attractions areas, street/meters, and cultural/ sports centers due to the duration of people usually parking. The automobile industry has received a new spiral of development with the advent of electric vehicles, so it is extremely important to create a wellfunctioning infrastructure for the servicing of electric vehicles, namely the network of charging stations. This project paid a special attention to the market of charging stations in the City of San Diego by identifying problems on the existing network and proposed a mathematical model for the development of this network.

Table 11 Analysis of demand number of chargers by zip code

\begin{tabular}{llllll}
\hline$\#$ & ZIP CODE & N (Number of EVs) & $\begin{array}{l}\text { Actual number } \\
\text { of EVSEs }\end{array}$ & $\begin{array}{l}\text { Demand number of EVSEs } \\
\text { (6 h model) }\end{array}$ & $\begin{array}{l}\text { Gap to fill (New } \\
\text { chargers need to install) }\end{array}$ \\
\hline 1 & 92,127 & 310 & 3 & 20.46 & -17.46 \\
2 & 92,130 & 467 & 15 & 30.82 & -15.82 \\
3 & 92,118 & 202 & & 13.33 & -13.33 \\
4 & 92,117 & 148 & 1 & 9.77 & -8.77 \\
5 & 92,104 & 125 & 1 & 8.25 & -7.25 \\
20 & 92,173 & 10 & 1 & 0.66 & 0.34 \\
21 & 92,014 & 1 & 1 & 0.07 & 0.93 \\
22 & 92,020 & 1 & 1 & 0.07 & 0.93 \\
23 & 92,071 & 2 & 2 & 0.13 & 1.87 \\
24 & 92,136 & 1 & 2 & 0.07 & 1.93 \\
25 & 92,105 & 41 & 5 & 2.71 & 2.29 \\
\hline
\end{tabular}




\section{Conclusions}

The distribution and capability of the existing charging networks in terms of electric vehicles, location, charging rate, and time of charging in San Diego was examined. A mathematical model to calculate the demand number of public Level 2 chargers for the City of San Diego and for each zip code was developed. The results showed that although San Diego city has enough chargers to accommodate the existing EV's charging demand, the current public charging distribution network is neither well designed nor effectively used. To eliminate the waste resulting from the inefficiently designed charging infrastructure and maximize the usage rate of each charger, it is recommended that the designed optimal model be utilized and the charging location priority be implemented to improve the availability and accessibility of a charging network in the City of San Diego. This model is easily applicable in the European environment since all the five significant independent variables $(\mathrm{B} / \mathrm{E}$ - Battery capacity to EV Range Ratio, D-Driver Traveling Distance, $\beta$ - Ratio of EV driver charges away from home, $\operatorname{Pref}_{L 2}$ percentage that EV driver prefers to charge on Level 2 stations, and $T_{L 2^{-}}$duration of public Level 2 chargers' work per day) are easy to obtain. The methodology developed could be transferred to European cities with reasonable little effort in order to contribute to the on-going debate.

\section{Acknowledgements \\ The authors would like to acknowledge the support provided by J.C. Martin and Randy Schimka of SDG\&E in conducting this research. Constructive suggestions provided by the reviewers of European Transportation Research} Review are acknowledged.

\section{Authors' contributions}

All authors read and approved the final manuscript.

\section{Competing interests}

The authors declare that they have no competing interests.

\section{Publisher's Note}

Springer Nature remains neutral with regard to jurisdictional claims in published maps and institutional affiliations.

Received: 2 March 2018 Accepted: 30 October 2018

Published online: 27 November 2018

\section{References}

1. Bosetti V, Longden T (2012) Light duty vehicle transportation and global climate policy: the importance of electric drive vehicles. Fondazione Eni Enrico Mattei (FEEM)

2. CA.Gov. (2012) Governor Brown announce $\$ 120$ million settlement to fund electrical Car charging stations across California. Office of Governor Edmund G.Brown Jr. Retrieved from http://gov.ca.gov/news.php?id=17463. Accessed 18 Mar 2018.

3. Romano P (2014) Utilities should help build electric vehicle charging Network. Retrieved from http://www.sacbee.com/opinion/op-ed/soapbox/ article3921605.html. Accessed 18 Mar 2018.

4. InsideEVs (2015) Monthly Plug-In Sales Scorecard. Retrieved from http://insideevs.com/monthly-plug-in-sales-scorecard/. Accessed 18 Mar 2018.
5. Cobb J (2014) Global Plug-in Car Sales Now Over 600,000. Retrieved from http://www.hybridcars.com/global-plug-in-car-sales-now-over-600000/. Accessed 18 Mar 2018.

6. Melaina M, Helwig M (2014) California Statewide Plug-in Electric Vehicle Infrastructure Assessment. National Renewable Energy Laboratory, Golden

7. Chung CY (2014) Electric vehicle smart charging infrastructure. Doctor of philosophy in mechanical engineering. University of California, Los Angeles

8. Knutsen D, Willen O (2013) A study of electric vehicle charging patterns and range Anxiety. Retrieved from http://www.diva-portal.org/smash/get/diva2: 626048/FULLTEXT01.pdf.

9. PlugShare, ChargePoint, Blink, and DOE/AFDC. (2015) Alternative Fueling Station Locator. Retrieved from: http://www.plugshare.com/; https://na. chargepoint.com/charge_point; http://www.blinknetwork.com/blinkMap. html; and http://www.afdc.energy.gov/locator/stations/results?utf8= \%E2\%9C\%93\&location=san+diego\&filtered=true\&fuel=all\&owner= all\&payment=all\&ev_level $1=$ true\&ev_level $2=$ true\&ev_dc_fast=true\&radius_ miles=5. Accessed 18 Mar 2018.

10. Cheng L, Chang Y, Wu Q, Lin W, Singh, C (2014) Evaluating charging service reliability for plug-in EVs from the distribution network aspect. Sustainable energy, IEEE transactions on, vol.5, no.4, (pp.1287-1296). Chung, Ching-yen. (2014). Electric vehicle smart charging infrastructure. UCLA: Mechanical Engineering 0330. Retrieved from http://www.afdc.energy.gov/locator/ stations/results?utf8=\%E2\%9C\%93\&location=sanhttp://www.escholarship. org/uc/item/07b6p3zk. Accessed 18 Mar 2018.

11. Green Fleet (2013) The latest development in EV battery technology. Retrieved on from https://www.greenfleetmagazine.com/155586/the-latestdevelopments-in-ev-battery-technology. Accessed 18 Mar 2018.

12. AeroVironment (2015) Different types of charging. Retrieved from http:// evsolutions.avinc.com/electric_vehicles/new_way_to_refuel/different_ways_ of_charging/. Accessed 18 Mar 2018.

13. Cunningham W (2011) Slow, Fast, and Faster: Where to Charge Electric Cars. Retrieved from http://www.cnet.com/news/slow-fast-and-faster-where-tocharge-electric-cars/. Accessed 18 Mar 2018.

14. Saxton, T. (2011). Understanding Electric Vehicle Charging. Retrieved from http://www.pluginamerica.org/drivers-seat/understanding-electric-vehiclecharging. Accessed 18 Mar 2018.

15. Gartner J (2013) EV Charging Networks Start to Unify. Retrieved from http:// www.plugincars.com/ev-charging-networks-start-unify-128628.html. Accessed 18 Mar 2018

16. PluginCars, PlugShare, Recargo (2013) The Rise of Electric Car Charging. Retrieved from http://www.recargo.com/news/infographics/the_rise_of_ electric_car_charging. Accessed 18 Mar 2018.

17. Bianco (2014) Seeing is believing: creating a new climate economy in the United States. World resources institute. Retrieved from http://www.wri.org/ publication/new-climate-economy. Accessed 18 Mar 2018.

18. EPRI (2012) SMUD smart charging pilot program. EPRI infrastructure working council. Retrieved from http://mydocs.epri.com/docs/publicmeetingmaterials/1203/ JKN2SD37ZWH/D2_PEV_Presentations_Combined.pdf. Accessed 18 Mar 2018.

19. SANDAG (2013) San Diego regional plug-in electric vehicle (PEV) readiness plan. California Center for Sustainable Energy. Retrieved from https:// energycenter.org/sites/default/files/docs/nav/programs/pev-planning/sandiego/San_Diego_PEV_Readiness_Planning_Guide-2013_low-resolution.pdf. Accessed 18 Mar 2018

20. National Academy of Sciences (NAS) (2013) Overcoming barriers to electricvehicle deployment. The National Academies Press, Washington, D.C.

21. Csonka B, Csiszár C (2017) Determination of charging infrastructure location for electric vehicles. Transportation Research Procedia 27:768-775

22. Gnann T, Funke S, Jakobsson N, Plötz P, Sprei F, Bennehag A (2018) Fast charging infrastructure for electric vehicles: Today's situation and future needs. Transp Res D 62:314-329

23. Kleiner F, Brokate J, Blaser F, Friedrich HE (2018) Quantitative analysis of the public charging-point evolution: a demand-driven spatial modeling approach. Transp Res D 62:212-224

24. Efthymiou D, Chrysostomou K, Morfoulaki M (2017) Aifantopoulou G (2016) electric vehicles charging infrastructure location: a genetic algorithm approach. Eur Transp Res Rev 9:27

25. NREL (2014) California statewide plug-in electric vehicle infrastructure assessment. National renewable energy laboratory. Retrieved from http://www.energy.ca.gov/2014publications/CEC-600-2014-003/CEC-6002014-003.pdf. Accessed 18 Mar 2018. 
26. Gridtest Systems (2015) EV Emulator Tool - Lab Version EVE-100L. Retrieved from http://www.testwall.com/datasheets/EVEmulatorEVE-100L7-28.pdf. Accessed 18 Mar 2018.

27. Smart J. Schey S. (2012) Battery Electric Vehicle Driving and Charging Behavior Observed Early in The EV Project. SAE international. Retrieved from https://www1.eere.energy.gov/vehiclesandfuels/avta/pdfs/evproj/nissan_ leaf_driving_charging_slides.pdf. Accessed 18 Mar 2018.

28. U.S. Department of Energy. (2015) Developing Infrastructure to Charge PlugIn Electric Vehicles. Retrieved from http://www.afdc.energy.gov/fuels/ electricity_infrastructure.html. Accessed 18 Mar 2018.

\section{Submit your manuscript to a SpringerOpen ${ }^{\mathcal{O}}$ journal and benefit from:}

- Convenient online submission

- Rigorous peer review

- Open access: articles freely available online

High visibility within the field

- Retaining the copyright to your article

Submit your next manuscript at $\boldsymbol{\nabla}$ springeropen.com 